\title{
Perceptions of Self-concept and Self-presentation by Procrastinators: Further Evidence
}

\author{
Joseph R. Ferrari ${ }^{1}$ and Juan Francisco Díaz-Morales ${ }^{2}$ \\ ${ }^{1}$ DePaul University \\ ${ }^{2}$ Universidad Complutense
}

\begin{abstract}
Two samples of university students completed self-report measures of chronic procrastination and either self-concept variables (Sample 1, $\mathrm{n}=233$ ) or self-presentational styles (Sample 2, $\mathrm{n}=210$ ). Results indicated that procrastination was significantly related to a self-concept of oneself as dominated by issues related to task performance, and to self-presentation strategies that reflected a person as continually justifying and excusing task delays and being "needy" of others' approval. It seems that men and women procrastinate in order to improve their social standing by making their accomplishments seem greater than they really are.

Keywords: procrastination, self-concept, self-presentation
\end{abstract}

Dos muestras de estudiantes universitarios completaron auto-informes de procrastinación crónica y de variables de auto-concepto (Muestra $1, n=233$ ) o de estilos de autopresentación (Muestra 2, $n=210$ ). Los resultados indicaron que la procrastinación se relaciona significativamente con el auto-concepto de una persona que se siente dominada por los asuntos relacionados con la ejecución de tareas, y con estrategias de autopresentación que reflejan una persona que constantemente justifica y excusa los retrasos en las tareas y necesita la aprobación de los demás. Parece que los hombres y las mujeres procrastinan para mejorar su estatus social haciendo que sus logros parezcan más importantes de lo que realmente son.

Palabras clave: procrastinación, auto-concepto, auto-presentación

The authors express their gratitude to Clarry Lay for his guidance and suggestions in editing an early version of the present paper, and Mark Driscoll for his data collection, entry, and initial analyses. Portions of this paper were presented at the 2002 annual meetings of the Eastern Psychological Association (Boston, MA, USA) and Midwestern Psychological Association (Chicago, IL, USA).

Correspondence should be sent to the first author at the Department of Psychology, DePaul University, 2219 North Kenmore Avenue, Chicago, IL, 60614 (United States). Phone: (773) 325-4244. email: jferrari@ depaul.edu 
Procrastination can be defined as a needless delay of a relevant and timely task. As many as $20 \%$ of North and South American as well as European men and women may be characterized as self-reporting dispositional chronic procrastination (Ferrari, O'Callahan, \& Newbegin, 2004; Ferrari, Díaz-Morales, O'Callaghan, Díaz, \& Argumedo, in press). Chronic procrastination is related to a host of traits, including low self-confidence and self-esteem and high depression, neurosis, self-awareness, social anxiety, forgetfulness, disorganization, non-competitiveness, dysfunctional impulsivity, behavioral rigidity, and lack of energy (Beswick, Rothblum, \& Mann, 1988; Ferrari, 2004; Ferrari, Johnson, \& McCown, 1995; Lay, 1986; Senecal, Koestner, \& Vallerand, 1995). Reviews of the literature also suggest that procrastination is related to low conscientiousness, low self-esteem, and low self-efficacy (van Eerde, 2003; 2004).

People who report frequent procrastination engage in self-sabotaging behaviors (Ferrari \& Tice, 2000), fraudulent excuse making (Ferrari, 1993), poor self-regulation of their performance skills within limited time frames (Ferrari, 2001), and they attribute task delays to factors other than their own performance (Ferrari et al., 1995). Although different motives for procrastination have been identified (Ferrari \& DíazMorales, in press), fear of failure may be a primary motive (Solomon \& Rothblum, 1984), and people report that they delay more on tasks they perceive as unpleasant, boring, or difficult (Milgram, Sroloff, \& Rosenbaum, 1993).

In short, procrastination is a complex construct relating to a variety of personality variables and involving more than ineffective time management (Ferrari et al., 1995; Steele, in press). An important goal for procrastination research is the analysis of the personality style of people who engage in frequent task delay. That is, there is a need for research to examine a set of integrated personality traits in order to determine the characteristics of procrastinators. In the present study, we examined two important global or integrated theoretical cognitive and behavioral aspects of procrastination that were investigated by previous social and personality research: self-concept and self-presentation styles.

A large representative set of cognitive dimensions identify a person's self-concept, the totality of one's thoughts and feelings toward the self (Gecas, 1982; Rosenberg, 1979). Because procrastinators are undependable about getting tasks accomplished on time, procrastination tendencies would be related to low dependency, trustworthiness, or reliability in completing tasks (van Eerde, 2003). Whereas this prediction simply seems to reiterate the definition of procrastination, no published studies have reported that these self-concept variables were held personally by procrastinators. Furthermore, procrastinators report that they often depend on others to accomplish their tasks (Ferrari, 1994). No published study has examined whether procrastinators see themselves as vulnerable and easily dominated by others. In the present study, procrastination was expected to be related to low levels of personal power over situations and feeling vulnerable about mistakes, as well as being easily embarrassed in front of others (both reflecting low selfconfidence and self-esteem: Ferrari, 2004; van Eerde).

Social psychologists have long been interested in the tactics and strategies people employ to manage the social impressions they present to others, a strategy known as selfpresentation (Schlenker, Dlugolecki, \& Doherty, 1994; Tedeschi, 1981). Previous studies found that procrastinators are very concerned about their public image and are selfconsciousness, and they tend to manipulate their public impression (Ferrari et al., 1995; Ferrari, 1991a). However, no prior study has examined the potential variety of selfpresentational styles that chronic procrastinators may employ. Given the literature linking behavioral self-handicapping and sabotage by procrastinators (Ferrari, 1991b; Ferrari \& Tice, 2000; see also Steele, in press), in the present study, individuals who report strong procrastination tendencies were expected to use self-presentational tactics that reflected defensiveness to protect their self-esteem (such as selfhandicapping, excuse-making, and justifying failures). Therefore, it was expected that chronic procrastinators would try to act self-assured to improve their public image by presenting themselves as special, and to evaluate other competitive people negatively.

\section{Method}

\section{Participants}

Two samples of university students attending the same large, urban, mid-western U.S. private university participated in the present studies as partial fulfillment of a course requirement in Introductory Psychology. None of these students belonged to more than one sample. In Sample 1, there were 210 participants (134 women, 75 men; $M_{\text {age }}=$ 19.1 years old, $S D=1.5)$ who were mostly $(80.4 \%)$ first year sophomore students and who reported a mean cumulative Grade Point Average of 3.3 ( $S D=0.6)$. In Sample 2, there were 233 participants ( 150 women, 83 men: $M_{\text {age }}=20.8$ years old, $S D=1.3$ ) who also were mostly lower division students $(77.4 \%)$ and who claimed a mean cumulative Grade Point Average of $3.5(S D=0.2)$.

\section{Measuring Instruments}

Adult Inventory of Procrastination (AIP; McCown, Johnson \& Petzel, 1989; see Ferrari et al., 1995, for details). Participants of both samples completed this unidimensional inventory, which examines procrastination motivated by fears of success or failure, avoidance of disclosure of skill inabilities, and performance insecurities (Ferrari, 1991a). Respondents rated 15-items on a 7-point Likert scale (1 = strongly disagree; 7 = strongly agree), with seven items 
reverse-scored. Extensive literature indicates that the AIP has construct, predictive, convergent, and divergent validities (see Ferrari et al., 1995; Ferrari \& Pychyl, 2000; DíazMorales, Ferrari, Díaz, \& Argumedo, 2006). Sample items included "I don't get things done on time" and "I am not very good at meeting deadlines." The AIP has good temporal stability (1 month, retest $r=.80$ ) and internal consistency $(\alpha \geq$.70; McCown, Johnson, \& Petzel).

Six-Factor Self-Concept Scale (SFSCS; Stake, 1994). The SFSCS is a 36-item multi-dimensional inventory designed to evaluate cognitive self-perceptions using descriptive adjectives or phrases (e.g., pleasant, have special talent) across six domains, with each phrase rated on 7-point scales $(1=$ never/almost never true of you; $7=$ always/almost always true of you). These domains reflect six constructs of self-concept, namely: (a) Task Accomplishment, having good work habits and an ability to manage and complete tasks effectively (hard worker, good at meeting deadlines); (b) Morality, having qualities valued as virtuous and reliable (trustworthy, dependable); (c) Vulnerability, self-critical, difficulty performing under pressure (easily embarrassed, makes mistakes); (d) Power, having strength and toughness (dominance, forceful); (e) Giftedness, having special natural ability and talents (innate ability, natural talent); and . (f) Likeability (pleasant and enjoyable to be with). Stake and others (Yanico \& Lu, 2000) report satisfactory construct validity with diverse university students. The SFSCS subscales have good temporal stability over one month $(r$ ranges from .76 to .86$)$ and acceptable internal consistency ( $\alpha$ ranges from .64 to .83).

Self-Presentational Tactics Scale (SPT; Lee, Quigley, Nesler, Corbett, \& Tedeschi, 1999). This 63-item inventory yields 12 subscales assessing a person's various behavioral strategies for impression management with statements rated on 9-point scales ( 1 = very infrequently; $9=$ very frequently). These subscales include: (a) Self-handicapping, the production of obstacles to success to prevent inferences about one's failure; (b) Excuse-making, verbal statements that deny personal responsibility for negative events; (c) Justification, the presentation of overriding reasons for negative behaviors as justified; (d) Disclaimers, trying to explain negative events before they occur; (e) Apologies, confessing personal faults for negative events; (f) Ingratiation, performing acts to earn others' approval in order to gain some advantage; (g) Blasting, behaviors intended to produce negative evaluations of others; (h) Enhancement, persuading others that an event's outcome is more positive than it actually is; (i) Supplication, presenting oneself as weak and dependent on others; (j) Intimidation, acts that present one's image as a powerful and dangerous person; (k) Exemplification, behavior presented as morally worthy and possessing integrity to elicit respect from others; and, (1) Entitlement, claims of responsibility and credit for positive achievements. Lee et al. reported that scores on the SPT scale have good temporal stability over several weeks ( $r$ ranges from .87 to .88 ), internal consistency (_ ranges from .86 to .93), and construct validity as a measure of actual behaviors reflecting impression management.

\section{Procedure}

During a testing session, after returning a signed consent form, participants completed within 20-25 minutes, in counterbalanced order, the AIP and either the SFSCS (Sample 1) or the SPT (Sample 2). Following participation, all students were presented a very brief overview of the study and the concept of procrastination.

\section{Results and Discussion}

Table 1 presents the mean AIP and alpha coefficient for participants in Samples 1 and 2. Preliminary analyses included a $2 \times 2$ (Group: Sample 1 vs. $2 \times$ Sex: women vs. men) ANOVA on AIP scores. There were no significant group or sex differences. These results are consistent with most other studies where procrastination rates were similar for men and women (see Ferrari et al., 1995; Ferrari \& Pychyl, 2000). Therefore, no further sex comparisons were performed in the present study.

Next, using zero-order correlates, we examined selfreported procrastination tendencies related to self-concept (see Table 1). The present study was the first time procrastinators actually were asked to reflect on their own self-concept. Given previous theoretical speculation about chronic procrastination (e.g., van Eede, 2003), it was expected that procrastination scores would be related negatively to self-concept variables of Task Accomplishment and Morality (i.e., dependability and reliability). As noted in Table 1, this hypothesis was supported. These zero-order correlates indicated that procrastination was significantly related to several defensive and assertive self-presentation styles, for example, continual use of self-handicapping, excuse-making, and justifications. It seems that procrastinators are aware that they sabotage their behaviors, in accordance with previous experimental studies where self-handicapping tendencies were examined (Ferrari, 1991b; Ferrari \& Tice, 2000). Procrastinators continually defended themselves against reproach. There also was a significant relation between procrastination and Ingratiation, Supplication, Blasting, and Enhancement (see Table 1).

We also examined the loadings of a set of cognitive selfconcept variables on procrastination, using a maximum likelihood factor analysis (varimax rotation). Table 2 shows a two-factor solution with Eigenvalues greater than 1.00, explaining $55.62 \%$ of the common variance. Using a .40 factor loading criterion, Task Accomplishment and Morality loaded negatively on chronic procrastination. 
Table 1

Mean Score, Coefficient Alpha, and Zero-order Correlates between Procrastination and Self-concept and Self-presentation Attributes

\begin{tabular}{|c|c|c|c|}
\hline & $M(S D)$ & $\alpha$ & Correlation with Procrastination \\
\hline \multicolumn{4}{|l|}{ Sample $1, n=210$} \\
\hline Chronic Procrastination: & $36.50(12.50)$ & .84 & - \\
\hline \multicolumn{4}{|l|}{ Self-concept factors: } \\
\hline Task accomplishments & $23.61(5.33)$ & .86 & $-.677 * * *$ \\
\hline Morality & $29.90(4.40)$ & .72 & $-.326^{* *}$ \\
\hline Vulnerability & $33.24(6.41)$ & .75 & $.196^{*}$ \\
\hline Power & $30.78(7.11)$ & .81 & $-.163 *$ \\
\hline Likeability & $25.11(5.15)$ & .84 & $-.151 *$ \\
\hline Giftedness & $21.55(5.43)$ & .78 & -.117 \\
\hline \multicolumn{4}{|l|}{ Sample $2, n=233$} \\
\hline Chronic Procrastination: & $35.70(10.44)$ & .83 & - \\
\hline \multicolumn{4}{|l|}{ Self-presentational tactics: } \\
\hline Self-Handicapping & $15.88(6.00)$ & .76 & $.291 * * *$ \\
\hline Excuse-Making & $20.55(7.80)$ & .83 & $.240 * *$ \\
\hline Justification & $22.90(8.51)$ & .81 & $.207^{*}$ \\
\hline Disclaimer & $28.61(6.64)$ & .75 & -.007 \\
\hline Apology & $23.11(6.01)$ & .75 & .069 \\
\hline Ingratiation & $32.50(9.80)$ & .77 & $.240 * *$ \\
\hline Supplication & $14.91(5.44)$ & .69 & $.223 * *$ \\
\hline Blasting & $19.33(8.20)$ & .70 & $.197 *$ \\
\hline Enhancement & $18.54(6.41)$ & .78 & $.167 *$ \\
\hline Intimidation & $17.71(7.12)$ & .82 & .138 \\
\hline Exemplification & $21.11(6.70)$ & .78 & .082 \\
\hline Entitlement & $20.50(6.40)$ & .71 & .067 \\
\hline
\end{tabular}

Note. Sample 1: $* p<.01 . * * p<.001 . * * * p<.0001$.

Sample 2: $* p<.01 . * * p<.001 . * * * p<.0001$.

Table 2

Rotated Factor Structure (Varimax Rotation) for Procrastination and Self-concept Scores with Sample 1

\begin{tabular}{|c|c|c|}
\hline Personality Variable & Factor 1 & Factor 2 \\
\hline Procrastination & -.811 & \\
\hline \multicolumn{3}{|l|}{ Self-concept } \\
\hline Task Accomplishment & .803 & \\
\hline Morality & .401 & \\
\hline Giftedness & & .759 \\
\hline Power & & .634 \\
\hline Likeability & & .433 \\
\hline Vulnerability & & -.400 \\
\hline Eigenvalue & 2.54 & 1.37 \\
\hline Percentage of explained Variance & 36.29 & 19.33 \\
\hline
\end{tabular}

$n=210$

Factor analysis indicated that procrastinators relate their self-concept to task completion, as proposed by Ferrari et al. (1995). We also found that high procrastination scores were significantly related to believing that one is vulnerable to external pressures in life and has little power to control one's life, as well perceiving oneself as disliked by others. Whereas previous studies showed that procrastinators are not liked by others because of their frequent delays (Ferrari \& Patel, 2004), the present study was the first investigation to find that procrastinators believe that others do not like them, thus revealing awareness of this fact. 
Table 3

Rotated Factor Structure (Varimax Rotation) for Procrastination and Self-presentation Scores with Sample 2

\begin{tabular}{lccc}
\hline Personality Variable & Factor 1 & Factor 2 & Factor 3 \\
\hline PSP/entitlement & .836 & & \\
SP/intimidation & .591 & \\
SP/apology & .517 & & \\
SP/enhancement & .451 & .756 & .666 \\
SP/justification & & .589 & .550 \\
SP/handicapping & & .450 & .441 \\
SP/excuse-making & & & .656 \\
SP/supplication & & & .598 \\
SP/ingratiation & & & .587 \\
Procrastination & & 2.72 \\
SP/disclaimer & & 10.74 \\
SP/exemplification & 7.09 & 6.73 \\
SP/blasting & 44.40 & & \\
\hline Eigenvalue & & & \\
Percentage of explained Variance & & & \\
\hline
\end{tabular}

Note. $\mathrm{SP}=$ Self-Presentation. $n=210$.

Using maximum likelihood factor analysis (varimax rotation), we also examined the loadings of the above set of behavioral self-presentation styles on procrastination. Table 3 shows a three-factor solution with Eigenvalues greater than 1.00 , explaining $61.87 \%$ of the common variance. Using a .40 factor loading criterion, Selfhandicapping, Justification, Excuse-making, Supplication, and Ingratiation styles loaded on chronic procrastination. Taken together, it seems that procrastinators present themselves as "needy," in an attempt to protect their selfesteem.

This present study presents several limitations. For example, two independent samples of participants were used instead of the same persons completing all the measures. If all the participants had completed the same scales, it would have been possible to ascertain the way self-concept and self-presentation variables are associated with procrastination in the same person. In addition, all three measures were self-report inventories, and may therefore be related to some underlying negative aspects of self-esteem or other such factors. Moreover, it is not clear from the present study how procrastinators use these cognitive and behavioral strategies in actual performance. Nevertheless, the results paint a picture of chronic procrastinators as individuals who conceptualize their identity as related to task accomplishment. Moreover, these individuals, in order to improve their social standing, try to make their accomplishments seem greater than they really are by placing obstacles in their path (selfhandicapping) and stressing the difficulty of their accomplishments (enhancement). Furthermore, procrastinators seem use other tactics to improve the image they present to others by showing how special they are, ingratiating themselves with others, and blasting opposing groups. Future research needs to examine empirically each of these self-concept and self-presentation aspects of chronic procrastinators and determine under which conditions these variables influence task delay.

\section{References}

Beswick, G., Rothblum, E.D., \& Mann, L. (1988). Psychological antecedents of student procrastination. Australian Psychologist, 23, $207-217$.

Díaz-Morales, J.F., Ferrari, J.R., Díaz, K., \& Argumedo, D. (2006). Factorial structure of three procrastination scales with Spanish adult population. European Journal of Psychological Assessment, 22, 132-137.

Ferrari, J.R. (1991a). A preference for a favorable public impression by procrastination: Selecting among cognitive and social tasks. Personality and Individual Differences, 12, 1233-1237.

Ferrari, J.R. (1991b). Self-handicapping by procrastinators: Protecting social-esteem, self-esteem, or both? Journal of Research in Personality, 25, 245-261.

Ferrari, J.R. (1993). Christmas and procrastination: Explaining lack of diligence at a "real-world" task deadline. Personality and Individual Differences, 14, 25-33.

Ferrari, J.R. (1994). Dysfunctional procrastination and its relationship with self-esteem, interpersonal dependency, and self-defeating behaviors. Personality and Individual Differences, 15, 673-679.

Ferrari, J.R. (2001). Procrastination as self-regulation failure of performance: Effects of cognitive load, self-awareness, and time limits on 'working best under pressure.' European Journal of Personality, 15, 391-406. 
Ferrari, J.R. (2004). Trait procrastination in academic settings: An overview of students who engage in task delays. In. H.C. Schowuenburg, C. Lay, T.A. Pychyl, \& J.R. Ferrari (Eds.), Counseling the procrastinator in academic settings (pp. 1928). Washington, DC: American Psychological Association.

Ferrari, J.R., \& Díaz-Morales, J.F. (in press). Procrastination: Different time orientations reflect different motives. Journal of Research in Personality.

Ferrari, J.R., Díaz-Morales, J.F., O’Callaghan, J., Díaz, K., \& Argumedo, D. (in press). Frequent behavioral delay tendencies by adults: International prevalence rates of chronic procrastination. Journal of Cross-Cultural Psychology.

Ferrari, J.R., Johnson, J.L., \& McCown, W.G. (1995). Procrastination and task avoidance: Theory, research, and treatment. New York: Plenum Press.

Ferrari, J.R., O'Callahan, J., \& Newbegin, I. (2004). Prevalence of procrastination in the United States, United Kingdom, and Australia: Arousal and Avoidance delays among adults. North American Journal of Psychology, 6, 1-6.

Ferrari, J.R., \& Patel, T. (2004). Social comparisons by procrastinators: Rating peers with similar and dissimilar delay tendencies. Personality and Individual Differences, 37, 14931501.

Ferrari, J.R., \& Pychyl, T.A. (2000). Procrastination: Current issues and new directions. Corte Madera, CA: Select Press.

Ferrari, J.R., \& Tice, D.M. (2000). Procrastination as a self-handicap for men and women: A task avoidance strategy in a laboratory setting. Journal of Research in Personality, 34, 73-83.

Gecas, V. (1982). The self-concept. Annual Reviews of Sociology, 8, 1-33.

Lay, C.H. (1986). At last, my research article on procrastination. Journal of Research in Personality, 20, 474-495.

Lee, S.J., Quigley, B.M., Nesler, M.S., Corbett, A.B., \& Tedeschi, J.T. (1999). Development of a self-presentation tactics scales. Personality and Individual Differences, 26, 701-722.

McCown, W., Johnson, J., \& Petzel, T. (1989). Procrastination, a principal components analysis. Personality and Individual Differences, 10, 197-202.
Milgram, N.A., Sroloff, B., \& Rosenbaum, M. (1988). The procrastination of everyday life. Journal of Research in Personality, 22, 197-212.

Rosenberg, M. (1979). Conceiving the self. New York: Basic Books.

Schlenker, B.R., Dlugolecki, D.W., \& Doherty, K. (1994). The impact of self-presentations on self-appraisals of behavior: The power of public commitment. Personality and Social Psychology Bulletin, 20, 20-33.

Senecal, C., Koestner, R., \& Vallerand, R.J. (1995). Self-regulation and academic procrastination. Journal of Social Psychology, 135, 607-619.

Solomon, L.J., \& Rothblum, E. (1984). Academic procrastination: Frequency and cognitive-behavioral correlates. Journal of Counseling Psychology, 31, 503-509.

Stake, J.E. (1994). Development and validation of the six-factor self-concept scale for adults. Educational and Psychological Measurement, 54, 56-72.

Steel, P. (in press). The nature of procrastination: A meta-analytic and theoretical review of quintessential self-regulatory failure. Psychological Bulletin.

Tedeschi, J.T. (1981). Impression management theory and social psychological research. New York: Academic Press.

van Eerde, W. (2003). A meta-analytically derived nomological network of procrastination. Personality and Individual Differences, 35, 1401-1418.

van Eerde, W. (2004). Procrastination in academic settings and the Big Five model of personality: A meta-analysis. In H.C. Schouwenburg, C.H. Lay, T.A. Pychyl, \& J.R. Ferrari (Eds.), Counseling the procrastinator in academic settings (pp. 2940). Washington: American Psychological Association.

Yanico, B.J., \& Lu, T.G.C. (2000). A psychometric evaluation of the six-factor self-concept scale in a sample of racial/ethnic minority women. Educational and Psychological Measurement, 60, 86-99.

Received September 15, 2006 Revision received December, 20, 2006 Accepted January 17, 2007 